\title{
Postnonclassical methodology and application of virtual reality technologies in social research
}

\author{
Yury P. Zinchenko, Artem I. Kovalev, \\ Galina Ya. Menshikova*, Ludmila A. Shaigerova \\ Faculty of Psychology, Lomonosov Moscow State University, Moscow, Russia \\ *Corresponding author. E-mail: gmenshikova@gmail.com
}

\begin{abstract}
The postnonclassical paradigm has increasingly become a conceptual basis for social research in various fields in an attempt to overcome the limitations of the classical and non-classical approaches. Subjects of social research activities require changes in the paradigm at all levels of research: from the statement of the problem to the elaboration of the appropriate methods and the analysis of the research data. The search for new research methods, technologies and techniques plays a crucial role in this process. One of the most promising methods that has rapidly developed in recent years is the technology of virtual reality (VR). This technology is being widely applied to both natural science and social science research. In this article, we examine the possibilities of using VR technology for the resolution of current tasks in social research from the perspective of the postnonclassical approach.
\end{abstract}

Keywords: postnonclassical paradigm, social research, virtual reality technology, ethnic and racial attitudes, verbal and non-verbal communication, avatar

\section{Postnonclassical paradigm in social research and new information technologies}

In recent decades, social sciences in Russia and beyond have faced new challenges caused by ever-changing realities and the emergence of new phenomena, social risks and problems at various levels: from individual to interpersonal to intergroup to international. These problems include not only the individual's search for their own place in the rapidly changing environment and the necessity to address vital issues of distinct groups but also the search for new ways of removing threats to society and humanity as a whole.

Today, one of the most pressing problems (and the most topical issue in social research) is that of security on many different levels (Zinchenko, 2011; Zinchenko \& Zotova, 2014), along with security-related phenomena, such as terrorism (Zinchenko, Shaigerova, \& Shilko, 2011; Chaiguerova, \& Soldatova, 2013; Solda- 
tova, Shaigerova, \& Shlyapnikov, 2008), emergency situations (Soldatova, Zinchenko, \& Shaigerova, 2011), extremism (Zinchenko, 2014), social stability (Dontsov \& Perelygina, 2013), xenophobia (Soldatova, Nestik, \& Shaigerova, 2011), interethnic and intercultural communication (Poëppel \& Bao, 2011), migration of large groups of people and their adaptation to the host culture (Soldatova \& Shaigerova, 2002; Soldatova \& Shaigerova, 2015).

At the current stage of societal development, which has given exceptionally complex tasks to social science, the resources traditionally used in social research within the classical and non-classical approaches are insufficient. To overcome the limitations of these approaches, new frameworks are proposed, for example, the historical-evolutionary approach in psychology (Asmolov et al., 2014)

The postnonclassical paradigm has increasingly become a conceptual basis for social research in various fields (Mezzich et al., 2013; Pervichko \& Zinchenko, 2014; Zinchenko \& Pervichko, 2012a,b; Zinchenko \& Pervichko, 2013). The use of the postnonclassical paradigm is not limited to a simple change in the conceptual framework of social research. Complex developing systems, e.g., subjects of social research activities, require changes in the paradigm at all levels of research: from the statement of problem to the elaboration of methods and analysis of the research data. In this regard, there is a strong need for reviewing the philosophical and general scientific methodology, as well as the specific scientific methodology. The search for new research methods, technologies and techniques plays a crucial role in this process.

One of the most promising methods that has rapidly developed in recent years is the technology of virtual reality (VR). This relatively recently created technology, is widely applied to both natural science and social science research. In-depth analyses of the methodological peculiarities of applying VR technology to psychological research show that it can be efficiently used in cognitive, organizational, sport and many other branches of psychology (Zinchenko et al., 2010). Research activities performed by means of CAVE and HMD systems of virtual reality have made it possible to obtain new data about the processes of the formation of cognitive space maps (Lakhtionova \& Menshikova, 2013), the perception of 3D optical illusions (Menshikova, 2013) and testing of vestibular system dysfunctions (Kovalev et al., 2014). At the same time, the potential of VR technology has not been fully realized, and its application requires a deeper, well-rounded analysis.

We examine the possibilities of using VR technology for the resolution of current tasks in social research from the perspective of the postnonclassical approach.

\section{Researching social processes through the use of VR environments}

The timely character of VR-assisted research of social processes is determined by some scientific and applied tasks that are exceptionally difficult or impossible to fulfill by means of classical research methods (e.g., psychological interviews, questionnaires). These tasks include studying the processes of ethnocultural identification and the formation of racial and ethnic attitudes; analyzing the behavior of partners that belong to different cultures when arranging virtual communication and videoconferences; developing "virtual avatars" to diagnose and regulate social 
conflicts; and creating virtual scenes to develop specific skills of interaction with partners representing a different cultural background or a different ethnic group.

VR-assisted social research is ongoing in several areas: studying the peculiarities of social interaction with virtual partners (avatars); studying social skills through the use of virtual partners; studying and training social skills in virtual scenes initiating an emergency; developing methods of diagnostics and correction of social phobias (e.g., stage fright); and studying the role of non-verbal communication (the synchronization of hand/head/body micromovements) and proxemics. VR technologies are widely used in studying non-verbal behavior, personal space (Bailenson et al., 2003), social interaction skills (Guadagno et al., 2007; Fox \& Bailenson, 2009), the origins of prejudices and social stereotypes (Dotsch \& Wigboldus, 2008; Groom et al., 2009), social facilitation and inhibition (Blascovich et al., 2002; Hoyt et al., 2003).

We consider a few of the most promising avenues of VR-assisted social research. To start, we provide definitions of the terms used in the subsequent text. Virtual Reality Systems (VR) is a combination of hardware and software that allows users to become immersed in a three-dimensional virtual environment as well as interaction with this environment by impacting the sense organs. Virtual environment (VE) means simulating bits of real world using computers and sensory equipment and forming through people's senses: sight, hearing, smell, touch. Avatar is a computer-generated user's representation in the form of a three-dimensional model.

\section{Studying, diagnosing and training communication skills through VR technology}

Virtual environments have been developed and used to diagnose communication disorders and to train communication skills. A methodological technique to create virtual environments that help to form communication skills consists of studying the interaction between the user and a computer agent within the framework of a specific scenario. To objectify the interaction, researchers use on-line recordings of psychophysiological parameters (e.g., heartbeat rate, galvanic skin resistance). The data analysis allows psychologists to select interaction scenarios more efficient for the user. Such scenarios may be complexified depending on the training success. This methodology helps to create a vast number of various scenarios for different types of communication skills.

In particular, VR systems are extensively used for treating social anxiety disorders, e.g., speech anxiety. Virtual systems have been proved to be more efficient than online chats and videoconferences (Emmenlkamp, 2005). Equally important is the fact that a therapist can manipulate VR by increasing or decreasing its impact on the patient. For example, he can change the virtual audience's reaction to the speaker's words or actions (Anderson et al., 2005).

Jouriles and his colleagues (2011) used VR in their communication training for women who were afraid of getting into conversations with male strangers. Female students were placed into situations of face-to-face communication with real men and then with male avatars. The results showed that making the acquaintance of an avatar is easier, and this type of virtual training helps women to feel more confident when interacting with real men (Jouriles et al., 2011). 
The use of VR in communication training allows researchers to develop efficient methods of testing subjects' individual characteristics. In one of our tests, we created dynamic VRs that required a high degree of sustainable perception of 3D objects in motion whose impact made it possible to reveal a number of athletes that had more developed vestibular function (Menshikova et al., 2014). In other experiments, the use of VR systems in communication training allowed us to identify the shyest members of a group (Caplan, 2003). Such people are likely to communicate through social networks, thus avoiding face-to-face communication; for this reason, researchers try to decrease VR sound and visual diversity to lessen the stress in subjects when creating VRs for introverts (Stritzke et al., 2004). With this end in view, they shorten the period of eye contact between the subject and the avatar and create standard-looking avatars, i.e., ones resembling average members of the same social group the subject belongs to. One of the tests showed that female introverts preferred communicating with those avatars that looked like them, unlike female extraverts, who opted for avatars of a different nationality, wearing motley clothes and with different haircuts (Dunn et al., 2012). If such limitations are in place, the shy subjects readily interact with avatars and display less fear towards communication in comparison to communication with a real person. The same result was shown by Hammick and Lee (Hammick \& Lee, 2014) in the experiment where introverts discussed alcohol-related issues with real interlocutors. Although the subject-matter of the discussion was topical, the shy subjects remained reserved throughout the conversation and received high scores on the Trait-like Communication Apprehension Scale (McCroskey, 2009). However, when communicating with avatars, these subjects behaved more actively and eventually obtained significantly lower scores.

New VR tools for non-verbal communication are currently being developed and certified, for example, special haptic tools which provide tactile contact with virtual objects. Such tools may be successfully used in exploring face-to-face communication processes because touch strength may give an information about approval, persuasion and maintenance of social status The importance of using tactile information for the simulation of virtual scenes has been recently demonstrated in several studies (Robles-De-La-Torre, 2006; Bailenson \& Yee, 2007; Haans \& IJsselsteijn, 2005). So tactile sensations were investigated by means of joysticks that simulate a handshake and memorize its power and other parameters (Bailenson \& Yee, 2007). Tactile and kinesthetic sensations were studied by activating cutaneous receptors with mechanical, electric, or thermic vibrodevises (Haans \& IJsselsteijn, 2005). It was found that the activation of tactile contact considerably amplifies the Presence effect in a virtual environment as well as the sense of togetherness with the virtual surroundings. The authors also analyzed in detail some advanced models of "indirect touches", which are devices that via mobile receive and transmit the strength of a hand grip and warmth over distances. Such devices may be regarded, with various degrees of plausibility, as tools of virtual tactile contact.

The above-mentioned devises of non-verbal communication are necessary for the study of social processes using VR technology. Furthermore, the better VR tools simulate sensations and perception of real-life situations, the more reliable results obtained using VR technology. 


\section{Interaction with avatars in a virtual environment}

Several research activities in the field of the psychology of communication are devoted to the peculiarities of real people's interactions with 3D computer-generated characters: avatars and agents. The difference between avatars and agents is as follows: the former are controlled by humans, whereas the latter are operated by a computer program. Several factors were identified which influenced the degree to which a real person was ready to accept a virtual partner as a subject of social interaction, i.e., to be convincing and lead to the use of natural communication skills (Blascovich \& Beall, 2010):

- the degree of confidence that the virtual partner is in fact another person (an avatar) and not a programmed object (an agent);

- the manifestation of low-level (involuntary) behavioral reactions typical of any real man in a situation of real-life communication (e.g., involuntarily keeping a distance when talking to an avatar or the reaction of fear towards the avatar's aggressive behavior);

- the importance of the situation for the user : the higher the importance, the higher the user's requirements for realism of virtual environment

- communicative realism, i.e., the interrelation of verbal and non-verbal components of communication;

- the demographic characteristics of virtual partners: race, nationality, sex, appearance, age.

Studying the interaction with avatars in a virtual environment has revealed some consistent patterns, e.g., subjects preferred anthropomorphic (human-like) avatars (Nowak \& Rauh, 2005) and were likely to trust avatars whose sex and race were the same as theirs. The efficiency of communication between users and avatars can be increased, even in eye contact situations (Bente et al., 2007). Zhang and his colleagues (Zhang et al., 2006) investigated the specific non-verbal, non-derivative signals used by an observer when communicating with an avatar. A virtual environment was created where the subject was offered the role of a teacher of a foreign language who should interact with a virtual group of students. The group members displayed different levels of language knowledge and skills. The virtual environment was interactive: the subjects, along with non-verbal influences in their virtual toolbox, were able to move virtual inanimate objects, maintain eye contact with the members of the virtual group and use pointing gestures to attract the virtual students' attention. This interaction caused great interest among the subjects: at some point, they would start talking to the virtual students as if to real human beings. The experiment revealed a number of specific, non-verbal, prosodic and kinesthetic signals that the subjects used when interacting with virtual partners.

The VR methods helped researchers to explore various aspects of interaction between humans and avatars in virtual environments. In the process of communication between real and virtual partners, new effects were discovered, including the digital chameleon effect: the avatar's imitation of the subject's behavior raised the efficiency of their interaction (Bailenson \& Yee, 2005). The experiment situation was as follows: an avatar would deliver a pre-recorded three-minute speech (advising students to carry their ID on visiting campus) while manifesting two 
modes of non-verbal behavior. In one group, the avatar's head movements would repeat those of the subject with a four-second delay (this delay factor was empirically determined as optimal). In the other group, the avatar's head movements were random. The subjects were more likely to praise and agree with those avatars who imitated their non-verbal behavior. In other words, the virtual partner that behaved in a more realistic way, e.g., imitated the interlocutor's head micromovements, was perceived as more trustworthy.

Just as interesting are various types of research into interpersonal distances that humans keep when interacting with avatars, which is specifically important in intercultural communication. One of the tasks for such research activities is to study the interrelation between non-verbal behavior and the distance that is most convenient for interaction with an avatar. The theoretical premise for this type of research is a hypothesis about the interrelation between non-verbal and spatial components of communication (Argyle \& Dean, 1965). According to the hypothesis, there is a balance between such systems of non-verbal communication as tactile contact, visual interaction (eye contact) and interpersonal distance. When one of these systems is excessively involved, the others are inhibited. For example, an intense tactile contact causes lesser eye contact; the same repression of eye contact occurs when the communication distance is shortened. The change in the ratio of non-verbal behavior systems is due to the need for the development of an optimal communication mode. This hypothesis was tested in studies on the interaction between humans and virtual avatars. Bailenson and his colleagues (2003) investigated the impact of various factors on the interpersonal distance. Each subject's behavior was observed in two different situations: 1 ) she/he was asked to come up to a motionless avatar to read and memorize the name and the number fastened to the shirt on the avatar's chest and spine, respectively; 2) she/he was asked to perceive an approaching avatar. The influence of the following factors was studied: 1 ) the subject's sex; 2 ) the avatar's sex; 3 ) perception of the virtual partner as an agent (i.e., a pre-programmed virtual object) or as an avatar (i.e., a virtual representation of a real human being) that had been formed by a set of instructions given before the experiment; and 4) eye contact: the avatar was looking at the subject or past him/her. In the process of communication, the behavioral responses of the subject during communication were registered, which allowed to assess the minimum distance between the subject and his/her virtual partner. Changes in the interpersonal distance were assessed separately for situations where eye contact was/was not involved, for different types of visual partners (avatar/agent) and for situations where the partners were of the same/different sex. The important factors influencing the subject's decision to install shorter interpersonal distance were the subject's sex, the avatar's sex, and the direction of the avatar's gaze. Equally important was the subject's perception of the virtual partner. The interpersonal distance was much shorter with avatars than agents in both female and male samples. Eye contact resulted in an increased interpersonal distance when interacting with avatars for the subjects of both sexes. Thus, Argyle and Dean's hypothesis was plausible and was able to explain the following peculiarity of real humans' communication with virtual partners: people are inclined to maintain a psychologically comfortable distance during communication by manipulating either the interpersonal distance or eye contact. The obtained data also support the basic hypothesis that it is possible to use virtual environments with 
avatars to study communication processes because the same patterns were revealed for real-life communication (Bailenson et al., 2003) .

In another paper (Bailenson et al., 2008), the authors analyzed the issue of setting an interpersonal distance between the user and so called the self-avatar which was collocated with the user's face and body in the real world. They assumed that the closest distance would be set with the self-avatar, particularly with those avatars that had the user's photographic resemblance. The participant was instructed to go around and carefully examine the avatar that was represented either a strangeravatar or a self-avatar. In addition, the self-avatar could be shown with a high or low degree of photographic resemblance. The subjects' behavior was monitored by video camera. At the end, the subjects were asked to fill out questionnaires to reveal their attitude towards the avatar as well as the degree of embarrassment in close proximity to the avatar. The avatar's sex and three degrees of resemblance between the avatar and the subject ("like me," "not quite like me," "a stranger") were chosen as variables. The avatar's behavior was pre-programmed in the same manner: they blinked and turned their faces to the subject. The subject task was to approach an avatar within 1.5 meters, then go around and, in the end, to stand right in front and answer the questions while carefully examining the avatar. In the process of receiving answers, the interpersonal distance was recorded. The results confirmed the authors' initial hypothesis that the mean minimum distance increased when decreasing degree of embarrassment. The "like me" and "not quite like me" avatars (having a high and a low degree of photographic resemblance) scored the lowest value of embarrassment, while the "stranger" had the highest one.

The study of Guadagno and his colleagues (2007) tested the influence of male/ female sex and the behavioral realism in the avatars' actions on subject's credibility of a virtual scene. . By "avatar's behavioral realism", the authors mean the correlation between avatar's lip movements and the spoken words, avatar's blinking and head movements to maintain eye-contact. Virtual partners could be of either sex and differed from one another in terms of their behavioral realism. The subject was informed whether the virtual partner was a computer simulation (an agent) or represented another student (an avatar). The persuasiveness of the avatar's speech on a subject-matter (e.g., how important it is to obey the rules on campus) was assessed. The results showed that the subjects were inclined to trust avatar's speech of the same sex. A special questionnaire revealed the influence of behavioral realism on the persuasiveness of the avatar's speech: the higher the degree of the avatar's behavioral realism, the stronger its influence on humans. Also the complex correlation between the virtual partner's sex and the subject's perception of the partner as an avatar or an agent was revealed. If a virtual interlocutor was a pre-programmed agent, its influence was stronger when it looked like a male human. In contrast, an avatar represented as another student was more convincing if it looked like a female.

\section{Using VR technologies in studies of racial prejudices and interethnic relations}

VR systems make it possible to efficiently study racial and ethnic attitudes. This effect is achieved through the use of virtual embodiment technology. The basic idea of this technology is to evoke virtual-body-ownership illusion - virtual embodi- 
ment experiences in which a person accepts a virtual body as a replacement for his or her own. The technology poses some distinct challenges, for example, it allows to initiate a virtual experience of being an avatar of different race or ethnicity. It was supposed putting somebody in the skin of a black avatar could reduce implicit racial bias (IRB). For example, it was shown the decrease in IRB scores when participants were placed in a coalition with members of another racial group (Kurzban et al., 2001). The virtual-body-ownership illusion could be induced experimentally by using a virtual mirror in which the participant would see her/his own virtual body. Experiencing the ownership illusion may be enhanced by the body's movements, although even in the absence of motion it may remain as strong. The social stereotypes formed during the experience of the ownership illusion were so strong that they manifested themselves even in simple behavioral acts. For example, lightskinned subjects being embodied in black-skinned avatars played the virtual drums of an African tribe much more ardently compared with the situation when they were embodied in light-skinned avatars or played the real drums in the real nondigital world (Kilteni et al., 2013).

The study by Groom, Bailenson and Nass (2009) investigated how the race of the subject's own avatar influenced the subject's racial attitudes. The virtual embodiment technology was used to change an own avatar's appearance (including the racial features of its face). The participants were split into two groups. The subjects of the first group saw her/ his/ own avatar as a light-skinned person, whereas those of the second group were embodied in a dark-skinned people. The authors conjectured that watching one's own avatar as belonging to a different race would result in reducing implicit racial bias. The subject's behavioral reactions were observed in two situations: 1) when she/he was asked to imagine herself/himself as a human being of a different race; and 2) when she/he viewed herself/hisself embodied in an own avatar having distinct features of a different race (a different face skin color). The experiment was conducted to determine how people's implicit racial bias was affected by the race of their own avatar and also by the type of the model representation (imagined vs. embodied). Volunteers of different races participated in the experiment. In a virtual environment, the subjects were embodied in a light/ dark-skinned avatar and were asked to respond to the interviewer's questions . At the same time, they were (or were not) able to see their own avatar's face reflected in a virtual mirror. The interpersonal distance between the subject's own avatar and the avatar- interviewer was assessed as a measure of racial bias. After the experiment, the subjects were asked to fill out two questionnaires revealing their racial and racist prejudices: the Racial Argument Scale - RAS (Saucier \& Miller, 2003) and, in part, the Modern Racism scale (McConahay, 1986). In situations where the subject saw his/her own avatar, considerable differences were revealed between the results of explicit (questionnaire's scores) and implicit (the interpersonal distances) racial bias. When the subjects only imagined themselves as belonging to a different race, these differences were less pronounced, which indicates that the situations in which a subject's imagination was involved differed considerably from those where the subject could see his/her own avatar that had features of a different race. Subjects embodied in dark-skinned avatars tended to behave more friendly towards light-skinned counterparts than those embodied in light-skinned avatars. The authors concluded these data confirmed the hypothesis about the automatic activa- 
tion of racial prejudices. Other studies showed that light-skinned avatars were less likely to help a dark-skinned avatar in a virtual environment compared to avatars of the same race (Easwick \& Gardner, 2009). McCall and his colleagues (2001) revealed that in a virtual environment imitating a conflict situation the participants demonstrated increased aggression toward dark-skinned avatars than toward lightskinned avatars Mentioned above studies help researchers to develop new methods of assessment of racial prejudices by applying VR systems. The analysis of VRassisted social research activities has proved the efficiency of VR technologies in studying communication, personal space, racial and ethnic prejudices, friend/foe identification and avatars' communication abilities.

\section{Conclusion}

1. Virtual reality is becoming a highly efficient method of social research; therefore, systematic studies of methodology, ethic norms, and technological advantages for the development and implementation of VR technology in both the theory and practice of social research, are needed.

2. The analysis of VR technologies shows several methodological peculiarities that distinguish these technologies from the traditional methods of psychological lab experiments. Some of these peculiarities may be regarded as advantages when compared to the methods of classical experimental psychology, whereas others can be seen as new issues that require new types of analyses

3. VR-assisted experiments demonstrated that VR technologies can be effectively used in various fields of fundamental and applied psychology, namely, social and organizational psychology, psychotherapy and psychological rehabilitation, sports, safety and cross-cultural psychology.

4. The analysis of VR-assisted experiments in the field of ethnic prejudices and interethnic activities has shown that the potential of these technologies has not been fully realized. At the same time, the possible benefits of using these technologies in this field are manifold and may help psychologists to achieve research aims and to complete practical tasks (e.g., to form positive precepts, develop communication skills). VR technologies fulfill the postnonclassical approach to studying social phenomena and, therefore, need further development.

\section{Acknowledgements}

The research was supported by Russian Science Foundation, by the Grant 15-1800109.

The authors acknowledge partial support from M.V.Lomonosov Moscow State University Program of Development.

\section{References}

Argyle, M., \& Dean, J. (1965). Eye-contact, distance and affiliation. Sociometry, 28(3), 289-304. doi: $10.2307 / 2786027$

Anderson, P. L., Zimand, E., Hodges, L. F., \& Rothbaum, B. O. (2005). Cognitive behavioral therapy for public-speaking anxiety using virtual reality for exposure. Depression and Anxiety, 22(3), 156-158. doi: 10.1002/da.20090 
Asmolov, A., Shekhter, E., \& Chernorizov, A. (2014). Po tu storonu gomeostaza: istoriko-evolyutsionnyi podkhod k razvitiyu slozhnykh system [On the other side of homeostasis: Historical-evolutionary approach to development of complex systems]. Voprosy psikhologii [Issues in psychology], 4, 3-13.

Bailenson, J. N., Blascovich, J., Beall, A. C., \& Loomis, J. M. (2003). Interpersonal distance in immersive virtual environments. Personality and Social Psychology Bulletin, 29, 1-15.

Bailenson, J. N., \& Yee, N. (2005). Digital Chameleons: Automatic assimilation of nonverbal gestures in immersive virtual environments. Psychological Science, 16(10), 814-819.

Bailenson, J. N., \& Yee, N. (2007). Virtual interpersonal touch: Haptic interaction and co-presence in collaborative virtual environments. International Journal of Multimedia Tools and Applications, 37(1), 5-14.

Bailenson, J., Patel, K., Nielsen, A., Bajscy, R., Jung, S.-H., \& Kurillo, G. (2008). The effect of interactivity on learning physical actions in virtual reality. Media Psychology, 11, 354-376.

Bente, G., Eschenburg, F., \& Kraemer, N.C. (2007). Virtual Gaze. A pilot study on the effects of computer simulated Gaze in Avatar-based conversations. In Virtual Reality: Proceedings of 12th human-computer interaction International conference (22-27 July 2007, Beijing, China). Lecture Notes in Computer Science, 4563, 185-194. doi: 10.1007/978-3-540-73335-5_21

Blascovich J., Loomis J., Beall, A. C., Swinth, K.R., Hoyt, C. L., \& Bailenson, J. N. (2002). Immersive virtual environment technology as methodological tool for social psychology. Psychological Inquiry, 13, 103-124. doi: 10.1207/S15327965PLI1302_01.

Blascovich, J., \& Beall, A. (2010). Digital immersive virtual environments and instructional computing. Educational Psychology Review, 22, 57-69.

Caplan, S. E. (2003). Preference for online social interaction: A theory of problematic use and psychosocial well-being. Communication Research, 30(6), 625-648.

Chaiguerova, L., \& Soldatova, G. (2013). Long-term impact of terrorist attack experience on survivors emotional state and basic beliefs In V Congress of the Russian Psychological Society 14-18 February (Moscow). Procedia - Social and Behavioral Sciences, 86, 603-609. doi:10.1016/j.sbspro.2013.08.621

Dontsov, A. \& Perelygina, E. (2013). Tense situations and the significance and the significance of stability for psychological security. Psychology in Russia: State of the Art, 6(2), 20-31. doi:10.11621/pir.2013.0202

Dotsch, R., \& Wigboldus, D. H. J. (2008). Virtual prejudice. Journal of Experimental Social Psychology, 44(4), 1194-1198.

Dunn, R. A., \& Guadagno, R. E. (2012). My avatar and me - Gender and personality predictors of avatar-self discrepancy. Computers in Human Behavior, 28, 97-106.

Eastwick, P.W., \& Gardner, W.L. (2009). Is it a game? Evidence for social influence in the virtual world. Social Influence, 4(1), 18-32.

Emmelkamp, P. M. G. (2005). Technological innovations in clinical assessment and psychotherapy. Psychotherapy and Psychosomatics, 74(6), 336-343.

Fox, J., \& Bailenson, J. N. (2009). Virtual self-modeling: The effects of vicarious reinforcement and identification on exercise behaviors. Media Psychology, 12, 1-25. doi: $10.1080 / 15213260802669474$

Groom, V., Bailenson, J. N., \& Nass, C. (2009). The influence of racial embodiment on racial bias in immersive virtual environments. Social Influence, 4(1), 1-18.

Guadagno, R. E., Blascovich, J., Bailenson, J. N., \& McCall, C. (2007). Virtual humans and persuasion: The effects of agency and behavioral realism. Media Psychology, 10, 1-22.

Haans, A., \& IJsselsteijn, W. (2005). Mediated social touch: A review of current research and future directions. Virtual Reality, 9(2-3), 149-159. 
Hammick, J. K., \& Lee, M. J. (2014). Do shy people feel less communication apprehension online? The effects of virtual reality on the relationship between personality characteristics and communication outcomes. Computers in Human Behavior, 33, 302-310.

Hoyt, C. L, Blascovich, J., \& Swinth, K. R. (2003). Social inhibition in immersive virtual environments. Presence: Teleoperators \& Virtual Environments, 12(2), 183-195.

Jouriles, E. N., Simpson Rowe, L., McDonald, R., Platt, C. G., \& Gomez, G. S. (2011). Assessing women's responses to sexual threat: Validity of a virtual role-play procedure. Behavior Therapy, 42(3), 475-484. doi: 10.1016/j.beth.2010.11.005

Kilteni, K., Bergstrom, I., \& Slater, M. (2013). Drumming in immersive virtual reality: The body shapes the way we play. Transactions on Visualization and Computer Graphics (IEEE), 19(4), 597-605. doi: 10.1109/TVCG.2013.29

Kovalev, A., Menshikova, G., \& Klimova, O. (2014). Figure skaters eye movements as indices of vection: VR study. In Proc. of 37-th European Conference on Visual Perception, (Belgrade, Serbia, August 24-28). Perception, 43, 105.

Kurzban, R., Tooby, J., \& Cosmides, L. (2001). Can race be erased? Coalitional computation and social categorization. PNAS, 98(26), 15387-15392. doi: 10.1073/pnas.251541498

Lakhtionova, I., \& Menshikova, G. (2013). Testing the ability of alocentric cognitive map acquisition using the CAVE technique. In S. Masalóva \& V. Solovyev (Eds.), Cognitive Modeling: Collection of Papers of the First International Forum on Cognitive Modeling (14-21 September, 2013, Italy, Milano-Marittima). Part 1. Cognitive Modeling in Linguistics: Proceedings of the XIV International Conference "Cognitive Modeling in Linguistics. CML-2013". (pp. 138141). Rostov-on-Don: Southern Federal University Press.

McCall, C., Blascovich, J., Young, A., \& Persky, S. (2009). Proxemic behaviors as predictors of aggression towards Black (but not White) males in an immersive virtual environment. Social Influence, 4(2), 138-154. doi: 10.1080/15534510802517418

McCroskey, J.C. (2009). Communication apprehension: What have we learned in the last four decades. Human Communication, 12(2), 157-171.

Menshikova, G. Ya. An investigation of 3D images of the simultaneous-lightness- contrast illusion using a virtual reality technique. Psychology in Russia: State of the Art, 6(3), 49-59. doi: 10.11621/pir.2013.0305

Mezzich, J. E., Zinchenko, Yu. P., Krasnov, V. N., Pervichko, E. I., \& Kulygina, M. A. (2013). Person-centered approaches in medicine: clinical tasks, psychological paradigms, and postnonclassic perspective. Psychology in Russia: State of the Art, 6(1), 95-109. doi:10.11621/ pir.2013.0109

Nowak, K. L., \& Rauh, C. (2005). The influence of the avatar on online perceptions of anthropomorphism, androgyny, credibility, homophily, and attraction. Journal of Computer-Mediated Communication, 11(1), 153-178.doi: 10.1111/j.1083-6101.2006.tb00308.x

Pervichko, E., \& Zinchenko, Yu. (2014). Epa-0571 - postnonclassical methodology in modern psychiatry and clinical psychology: Opportunities and perspectives. European Psychiatry, 29(1), 1. doi:10.1016/S0924-9338(14)77961-1

Poëppel, E., \& Bao, Y. (2011). Three modes of knowledge as basis for intercultural cognition and communication: A theoretical perspective. In: Sh. Han \& E. Poëppel (Eds.), Culture and Neural Frames of Cognition and Communication. (pp. 215-231). Heidelberg: SpringerVerlag. doi:10.1007/978-3-642-15423-2_14

Robles-De-La-Torre, G. (2006). The importance of the sense of touch in virtual and real environments. Special issue on haptic user interfaces for multimedia systems. IEEE Multimedia, 13(3), 24-30. doi: 10.1109/MMUL.2006.69

Soldatova, G., \& Shaigerova, L. (2002). Psikhologicheskaya adaptatsiya vynuzhdennykh migrantov [Psychological adjustment of forced migrants]. Psihologicheskij Zhurnal [Psychological Journal], 23(4), 8-28. 
Soldatova, G., Shaigerova, L., \& Shlyapnikov, V. (2008). Psikhologicheskie posledstviya terroristicheskogo akta: opyt Beslana [Psychological impact of a terrorist attack: The experience of Beslan]. Psihologicheskij Zhurnal [Psychological Journal], 30(6), 15-26.

Soldatova, G., Nestik, T., \& Shaigerova, L. (2011). Printsipy konstruirovaniya tolerantnosti i upravleniya riskami ksenofobii [The principles for construction of tolerance and management of xenophobia risks]. Nacional'nyj Psihologicheskij Zhurnal [National psychological journal], $2(6), 60-80$.

Soldatova, G., Zinchenko, Yu., \& Shaigerova, L. (2011). Terroristicheskii akt kak ekstremal'naya situatsiya v obshchestve riska [A terrorist attack as an extreme situation in the risk society]. Nacional'nyj Psihologicheskij Zhurnal [National psychological journal], 2(6), 98-112.

Soldatova, G. U., \& Shaigerova, L. A. (2015). Refleksiya mnozhestvennosti vybora v psikhologii mezhkul'turnykh kommunikatsii [Reflections on the multiple choice in psychology of intercultural communications]. Psikhologicheskie issledovaniya, 8(40), 10. Retrieved from: http:// psystudy.ru

Stritzke, W. G. K., Nguyen, A., \& Durkin, K. (2004). Shyness and computer-mediated communication: A self-presentational experiences. Media Psychology, 6, 1-22.

Styopin, V. S. (2003). Samorazvivajuwiesja sistemy i postneklassicheskaja racional'nost' [Selfdeveloping systems and postnonclassical rationality]. Voprosy Filosofii [Issues in philosophy], $8,5-17$.

Zhang, H., Yu, Ch., \& Smith, L. B. (2006). An interactive virtual reality platform for studying embodied social interaction. Retrieved from: http://www.androidscience.com/proceedings 2006/2Zhang2006SocialInteraction.pdf

Zinchenko, Yu. P., Menshikova, G. Ya., Bayakovsky, Yu. M., Chernorizov, A. M., \& Voiskounsky, A.E. (2010). Technologies of virtual reality in the context of World-wide and Russian psychology: methodology, comparison with traditional methods, achievements and perspectives. Psychology in Russia: State of the Art, 3, 11-45. doi: 10.11621/pir.2010.0001

Zinchenko, Yu. P., \& Pervichko, E. I. (2012a). The methodology of syndrome analysis within the paradigm of "qualitative research" in clinical psychology. Psychology in Russia: State of the Art, 5, 157-184. doi:10.11621/pir.2012.0010

Zinchenko, Yu. P., \& Pervichko, E. I. (2012b). Postneklassicheskaja metodologija v klinicheskoj psihologii: Nauchnaja shkola L. S. Vygotskogo-A. R. Lurija [Postnonclassical methodology in clinical psychology: Vygotsky-Luria school]. Nacional'nyj Psihologicheskij Zhurnal [National psychological journal], 2(8), 42-49.

Zinchenko, Yu. P. (2014). Extremism from the perspective of a system approach. Psychology in Russia: State of the Art, 7(1), 23-33. doi:10.11621/pir.2014.0103

Zinchenko Yu. P., \& Zotova, O. (2014). Security in the worldview of Russians. Psychology in Russia: State of the Art, 7(1), 50-61. doi:10.11621/pir.2014.0106

Zinchenko, Yu. P. (2011). Security psychology as social systemic phenomenon. Psychology in Russia: State of the Art, 4, 307-315. doi: 10.11621/pir.2011.0019

Zinchenko, Yu. P., \& Pervichko, E. I. (2013). Nonclassical and Postnonclassical epistemology in Lev Vygotsky's cultural-historical approach to clinical psychology. Psychology in Russia: State of the Art, 6(1), 43-56. doi:10.11621/pir.2013.0104

Zinchenko, Yu., Shaigerova, L., \& Shilko, R. (2011). Psikhologicheskaya bezopasnost' lichnosti i obshchestva $\mathrm{v}$ sovremennom informatsionnom prostranstve [Psychological safety of personality and society in contemporary informational environment]. Nacional'nyj Psihologicheskij Zhurnal [National psychological journal], 2(6), 48-59.

Original manuscript received August 02, 2015

Revised manuscript accepted October 14, 2015

First published online December 30, 2015 